\title{
Presenting two incongruent color words on a single trial does not alter Stroop interference
}

\author{
COLIN M. MACLEOD and SHELLEY L. HODDER \\ University of Toronto, Scarborough, Ontario, Canada
}

\begin{abstract}
Two experiments showed that having two incongruent words present on a single Stroop trial (e.g., both red and green in blue, say "blue") did not alter interference relative to having only one incongruent word. This was true whether the two incongruent words were presented successively at several stimulus onset asynchronies (Experiment 1) or simultaneously in adjacent positions (Experiment 2). We argue that the first word captures attention and "locks out" others, preventing additional interference.
\end{abstract}

In his introductory text, Gleitman (1991, p. 296) described the Stroop effect-the interference experienced when naming the color of ink in which an incompatible word is presented (e.g., say "red" to the word blue printed in red ink)-as "diabolical." Certainly the effect is powerful and provocative, which partially explains why psychologists have continued to seek an explanation of it since Stroop (1935) first reported it (for a review, see MacLeod, 1991). Very often, the preferred explanation has been in terms of what Gleitman graphically described as the "violent response conflict" between word and color, the dominant conception of the phenomenon since Dyer's (1973) influential review.

Using Morton's (1969) model as a springboard, Dyer $(1973$, p. 117) maintained that "the interference is not seen to occur prior to availability of the symbol name, and the interference is a form of response competition." He then merged this idea with Treisman's (1969) attentional account, arguing that "attention may have to be directed to the level (perhaps auditory) at which name responses to the sensory representations emerge" (Dyer, 1973, p. 118). Two years later, the response competition account became entrenched when, in setting out their views on automaticity, Posner and Snyder (1975, p. 57) said that "the usual Stroop effect arises because of response competition between vocal responses to the printed word and the ink color ... color naming and reading go on in parallel and without interference until close to the output."

Under such a response competition view, it would seem reasonable that more potential responses ought to give rise to more competition, and hence to more interference. To

This research was supported by Natural Sciences and Engineering Research Council of Canada Grant A7459. We are grateful to Douglas Bors and Marilyn Smith for their comments on the initial draft, and to Tony Greenwald and Geoffrey Loftus, as well as an anonymous reviewer, for their helpful reviews and advice. Correspondence should be addressed to C. M. MacLeod, Division of Life Sciences, University of Toronto at Scarborough, Scarborough, ON MIC 1A4, Canada (e-mail: macleod@ scar.utoronto.ca).

-Accepted by previous editor, Geoffrey R. Loftus date, only two studies have investigated such a situation. Along with their conditions of primary concern, Kahneman and Chajczyk (1983, Experiment 4) had subjects name the color of a color bar with one or two flanking words. When a single flanker word named another incongruent color, responses were slower $(706 \mathrm{msec})$ than when the flanker word was neutral $(637 \mathrm{msec})$, interference of $69 \mathrm{msec}$. However, adding a second incongruent flanker word had no additional impact $(700 \mathrm{msec})$, producing quite equivalent interference of $63 \mathrm{msec}$ measured against the same baseline.

In a follow-up on the Kahneman and Chajczyk (1983) study, Yee and Hunt (1991) also included the conditions of interest here. In their Experiment 1, they found that flanking the to-be-named color bar with one incongruent color word $(668 \mathrm{msec})$ versus two incongruent color words $(670 \mathrm{msec})$ both produced about the same amount of interference relative to a neutral control word $(629 \mathrm{msec})$, interference of approximately $40 \mathrm{msec}$. In their Experiment 3, they included both a two-incongruent-word condition $(656 \mathrm{msec})$ and a two-neutral-word control $(616 \mathrm{msec})$, again demonstrating $40 \mathrm{msec}$ of interference, this time against a twoitem baseline.

Although they included a condition with more than one competing color word response, the emphasis in these two studies was on the impact of neutral noncolor words. Furthermore, both studies used the nonintegrated version of the Stroop task, in which the word and the color are physically separated in the display and in which interference is considerably smaller than in Stroop's original integrated version. In the present study, we used the standard integrated color-word Stroop procedure to examine the impact of one versus two competing incongruent word responses. For generality, we chose to do this in two ways. Experiments $1 \mathrm{~A}$ and $1 \mathrm{~B}$ contrast the single-word case (e.g., red in green, say "green") to a sequential procedure in which a first color word is quickly replaced by a second one on the same trial before the subject can respond to the common color in which they are both printed (e.g., red for $150 \mathrm{msec}$ immediately replaced by blue, both in green, say "green"). Experiment 2 contrasts the single-color word 
case to the simultaneous presentation of two different color words, one above the other, each printed in the same incongruent ink color (e.g., the word red just above the word blue, both printed in green, the correct response being "green"). Will doubling the number of competing word responses affect the interference observed?

A simple response competition view would posit that the more potential responses that are available on a single trial, the more interference will occur. Thus, two words should interfere more than one, at least when both words are eligible responses (i.e., the names of colors in the response set). However, a key assumption of such a view is that processing occurs for more than one of the words on a given trial, at least to an extent sufficient to contribute to the disruption of color naming. Contrast this with a view that claims that only one word is processed sufficiently to interfere with color naming on a given trial: Early in processing, one word is selected to become the focus of further verbal processing, and processing ceases on any other words. This idea would be consistent with the notion of stimulus-driven attentional capture proposed by Yantis (1993). The present experiments test these two possibilities.

\section{EXPERIMENT 1}

If a subject begins to process a color-word stimulus but the word suddenly changes before he/she can respond to the color, surely this change would be detected. Sudden onsets in the focus of attention are virtually impossible to ignore, as the phenomenon of stimulus-driven attentional capture nicely demonstrates (see, e.g., Yantis, 1993). For this reason, we decided to try as our first manipulation the successive presentation on the same trial of two color words printed in the same incongruent color. Although the available evidence (Kahneman \& Chajczyk, 1983; Yee \& Hunt, 1991) suggests that the number of color words will not matter, there are at least three reasons to question the generality of this conclusion. First, these studies used nonintegrated stimuli, which produce much less interference than the traditional integrated stimuli. Second, the two words in these studies were presented simultaneously, minimizing the likelihood of stimulus-driven capture. And third, on most of the trials, the words were not color words, perhaps undermining the potency of the trials containing color words.

To accomplish the item change on two-item trials, the first item must appear for some specified duration before being replaced by the second item. The time from the appearance of the first item to its replacement by the second item is referred to as the stimulus onset asynchrony (SOA). Three SOAs were used in Experiment 1A: 50, 150, and $250 \mathrm{msec}$. These values were chosen to provide a reasonable range that would still be within the period before the subject could respond, thereby preventing trials in which the subject responded before the second item on the trial appeared. Note that when items were presented se- quentially, it made sense to rewrite the one-item trials on the screen at the appropriate SOAs so that they would parallel the two-item trials in this regard.

In addition to SOA, there is also the issue of interstimulus interval (ISI). In Experiment 1A, items were rewritten on the screen immediately at the specified SOA, for an effective ISI of $0 \mathrm{msec}$. This resulted in an obvious change on two-item trials (because the word was different) but an imperceptible interruption on one-item trials. To ascertain whether this "subjective confound" was crucial for our pattern of results, Experiment $1 \mathrm{~B}$ was carried out with a perceptible ISI gap of $70 \mathrm{msec}$ inserted between the two parts of each trial on both one-word and two-word trials. This resulted in SOAs of 120,220 , and $320 \mathrm{msec}$ (i.e., the SOAs of Experiment $1 \mathrm{~A}$ plus the 70-msec ISI gap). If simply noticing a visible change has an impact, Experiment 1B should equate the one-item and two-item conditions.

\section{Experiment 1A}

\section{Method}

Subjects. Twenty University of Toronto at Scarborough students participated for bonus points in introductory psychology. None were excluded on the basis of a preset maximum error rate of $.20 ; 1$ was excluded for exceptionally long latencies, many over $2 \mathrm{sec}$. The data of 19 subjects remained for analysis.

Design. There were three independent variables: type of item (incongruent word vs. control), number of items on each trial ( 1 vs. 2 ), and SOA between the two items on each trial $(50,150$, or $250 \mathrm{msec})$. All three were manipulated within subjects.

Items. There were four color words - red, blue, green, and yellow - and four corresponding control items matched for length with the color words- $w w w, x x x x$, sssss, and $\mathrm{mmmmmm}$. The four palate colors used to print items on the screen were 12 (red), 9 (blue), 2 (green), and 14 (yellow).

Apparatus and experimental control. Testing was carried out on IBM-compatible 286 computers equipped with Tatung CM-1496 14-in. VGA color monitors. Millisecond accuracy voice response timing was accomplished as follows. When a subject spoke into a Realistic Highball-7 microphone, the signal was amplified by a Realistic SA-150 stereo amplifier and input through a specially modified keyboard as if the hyphen key had been pressed. All programming was done in QuickBASIC 4.5 with millisecond accuracy timing routines taken from Graves and Bradley $(1987,1988)$. The screen background color was black (palate no. 0), and instructions and control stimuli were presented in white (palate no. 7). All materials were presented in regular 80-character-per-line font. Stimuli were presented in lowercase characters.

Procedure. Each trial in the experiment was set up as follows. First, there was a 250 -msec blank screen, then a 250 -msec warning, then a 250 -msec blank, and finally the presentation of the two successive elements of the stimulus, with the second element remaining on the screen until the subject responded. The warning consisted of a row of eight asterisks presented at the center of the screen on line 12. The stimulus consisted of two words or control strings presented in immediate succession and centered on line 12 . The first element was replaced by the second element after 50,150 , or $250 \mathrm{msec}$. (Note that this replacement of the first element by the second occurred for single-item trials as well as for two-item trials, although the change on single-item trials was not detectable by the subject.) On single-item trials, the two words or control strings were identical; on double-item trials, the two words or control strings were dif- 
ferent. Word(s) and color were always incongruent. Both of the words or control strings on a trial were always in the same color, with the task being to name that color as quickly as possible, ignoring the printed items.

Each subject completed 216 experimental trials. There were 144 two-item trials consisting of 24 two-word trials and 24 two-controlitem trials at each of the three SOAs. For both incongruent and control two-item conditions (two different color words vs. two different control items), each possible pair of items was presented in each of the remaining two colors twice, with each of the words in the pair appearing first once and second once. This pattern was repeated for each of the three SOAs. There were 72 one-item experimental trials consisting of 12 one-word trials and 12 one-control-item trials at each of the three SOAs. For both incongruent and control one-item conditions (one color word vs. one control item), each item was presented in every other color once at each SOA. All of the various trial types were intermingled in a unique random sequence for each subject.

Once the subject had named the color, the experimenter pressed a key to indicate whether the response was right or wrong. That keypress also initiated the next trial. Prior to the experimental trials, there were 18 practice trials made up of 12 two-item trials, two in each of the $2 \times 3$ (type of item $\times$ SOA) conditions, and 6 one-item trials, one in each of the $2 \times 3$ conditions. The materials on practice trials were randomly selected from the set of possible different trials. Subjects were encouraged to respond as quickly and as accurately as possible in naming the color on each trial. No feedback was given.

Data analysis. The primary mode of data analysis was graphical. The error bars in each panel of Figure 1 are $95 \%$ confidence intervals derived from a separate $2 \times 2$ analysis of variance (ANOVA) on that panel and calculated according to Equation 4 in Loftus and Masson (1994). Supporting $2 \times 2 \times 3$ repeated measures ANOVAs, with the factors being type of item (word vs. control string), number of items ( 1 vs. 2$)$, and SOA $(50,150$, or $250 \mathrm{msec})$, were conducted on the mean correct response latencies and on the mean proportions of errors. For the latency analysis, responses that took longer than $2,000 \mathrm{msec}$ were counted as errors; this happened on only .005 of all trials. The proportions of errors and the analyses of the error data appear in the Appendix. There was no suggestion of any speed-accuracy tradeoff; error patterns either coincided with latency patterns or showed no reliable differences.

\section{Results and Discussion}

The three panels on the left of Figure 1 display the response latency data from Experiment 1A separately for each of the three SOAs. Each panel shows the same pattern: Incongruent words interfered relative to neutral controls, and responses on trials with only one item were faster than those on trials with two items. SOA did not matter. Most critically, two incongruent color words caused no more interference than did one.

The straightforward graphical results are supported by the ANOVA results. Naming the color of words $(810 \mathrm{msec})$ was slower than naming the color of control items $(706 \mathrm{msec})$, indicating $104 \mathrm{msec}$ of Stroop interference $[F(1,18)=$ $\left.134.43, M S_{\mathrm{e}}=4,598.45, p<.001\right]$, a quite typical amount of interference. Responding to two items $(776 \mathrm{msec})$, whether words or control items, took $37 \mathrm{msec}$ longer than responding to a single item $[739 \mathrm{msec}, F(1,18)=37.28$, $\left.M S_{\mathrm{e}}=1,991.43, p<.001\right]$. Most important, the number of items and the type of items did not interact $(F<1)$.

As is apparent in Figure 1, SOA had very little effect. The main effect was nonsignificant $\left[F(2,36)=1.73, M S_{\mathrm{e}}=\right.$ $1,888.73, p=.19]$. Only the interaction of SOA with num- ber of items approached significance $\left[F(2,36)=3.05, M S_{\mathrm{e}}=\right.$ $1,616.16, p=.06]$. This suggested that the impact of two items versus one item was small at the $50-\mathrm{msec}$ SOA (17 msec) but larger at the 150 - and $250-\mathrm{msec}$ SOAs (44 and $46 \mathrm{msec}$, respectively). Perhaps subjects did not always notice the item switch at the shortest SOA.

The left panel of Figure 2 displays interference at each of the SOAs for both the one-item and the two-item conditions. The $95 \%$ confidence limits in this figure derive from a $3 \times 2$ ANOVA on the incongruent-control difference scores. There were no significant effects (all $F \mathrm{~s}<1.02$, $p s>.32$ ). Clearly, then, Stroop interference did not increase in moving from one to two incongruent words, regardless of the durations of the two words.

The effect of number of items could indicate simply that the change in items was noticed on two-item trials (equally for words and control items). If so, adding a perceptible gap between the two items on a single trial in Experiment $1 \mathrm{~B}$ should eliminate the effect of number of items because this gap would be apparent for both oneitem and two-item trials. If the gap introduced in Experiment $1 B$ eliminates the effect of number of items observed in Experiment 1A, then that effect was probably due to the perceptible change on two-item trials but not on one-item trials. If the gap in Experiment $1 \mathrm{~B}$ does not eliminate the effect of number of words, then that effect must be attributed to the number of items, not the perception of some change having occurred.

To summarize, presenting two to-be-ignored words in quick succession on the same trial did not reliably increase Stroop interference relative to that caused by a single word. Interference scores (word minus control item) were $99 \mathrm{msec}$ for the one-item case and $109 \mathrm{msec}$ for the twoitem case (.030 and .027 , respectively, for errors), and were essentially unaffected by the duration of the first item. Increasing the number of available potential responses on a single trial does not appear to affect Stroop interference, at least when those responses become available sequentially.

\section{Experiment 1B}

\section{Method}

Subjects. Fifteen new subjects from the same pool as that in Experiment 1A participated. Two were excluded on the basis of exceeding the preset maximum error rate of .25 , leaving the data of 13 for analysis. Note that error rates were slightly higher in Experiment $1 \mathrm{~B}$ in part because the criterion for exclusion was .25 rather than 20 .

Design, Apparatus, and Procedure. All experimental details were identical to those in Experiment 1 A with one exception. Instead of immediately replacing the first element of a trial with the second element when the SOA expired, a 70-msec blank gap was inserted on all trials. This was intended to make all trials have an obvious interruption between the two elements. Thus, the SOAs were now 120,220 , and $320 \mathrm{msec}$, corresponding to first element durations of 50,150 , and $250 \mathrm{msec}$ plus the $70-\mathrm{msec}$ blank.

Data Analysis. Data handling followed exactly the procedures of Experiment 1A. Counting latencies longer than $2,000 \mathrm{msec}$ as errors resulted in reclassification of .009 of all trials. Error data and analyses are presented in the Appendix. 

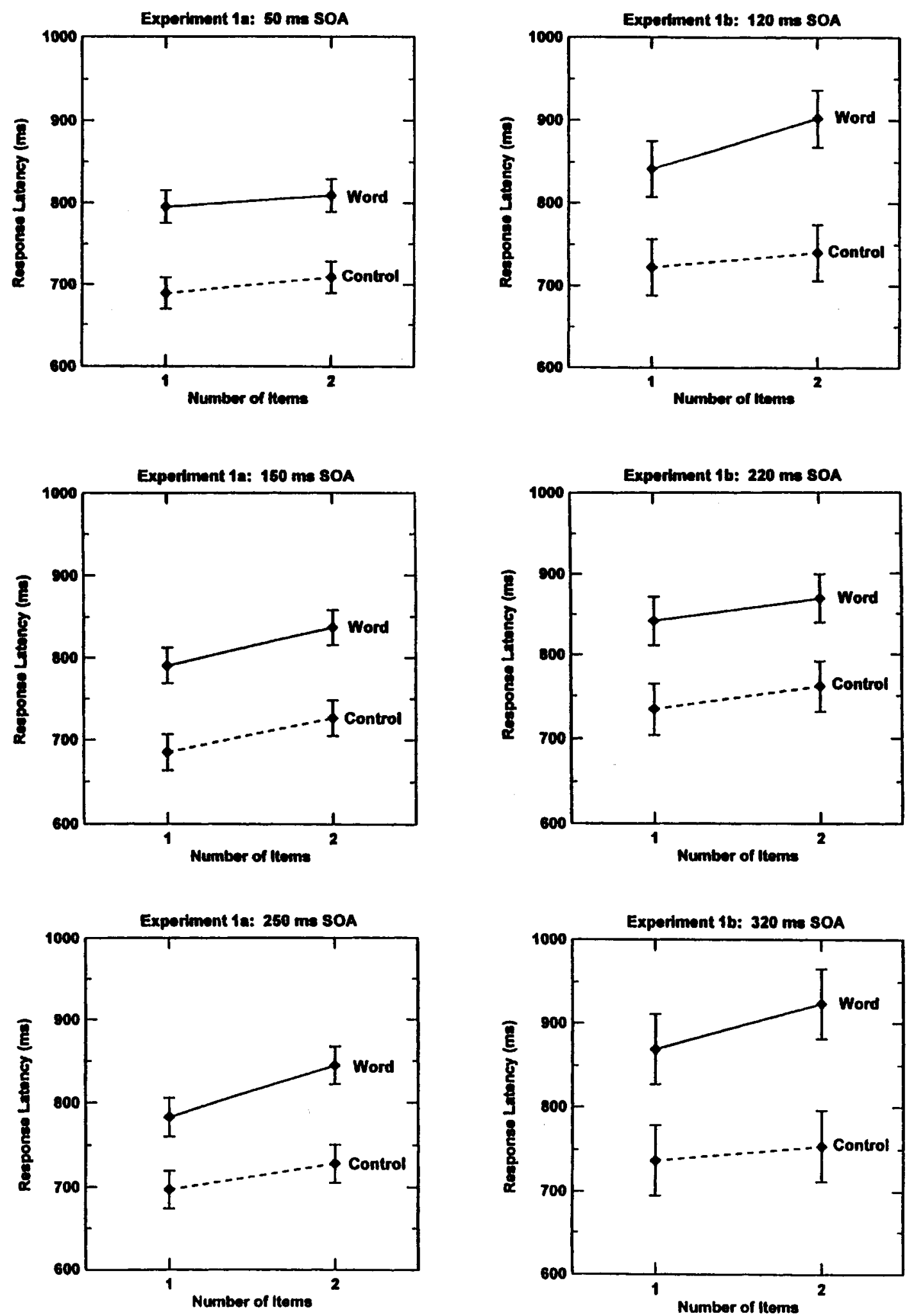

Figure 1. Experiment 1: Mean response latency for incongruent words and for neutral controls as a function of the number of different items on a trial ( 1 or 2 ). The error bars are $95 \%$ confidence intervals derived from indjvidual $2 \times 2$ ANOVAs on each panel and calculated according to Equation 4 in Loftus and Masson (1994). The three panels on the left show the data from Experiment 1A separately for each stimulus onset asynchrony (SOA) between the elements of a trial $(50,150$, or $250 \mathrm{msec})$. The three panels on the right show the data from Experiment $1 B$ separately for each SOA $(120,220$, or 320 msec). 

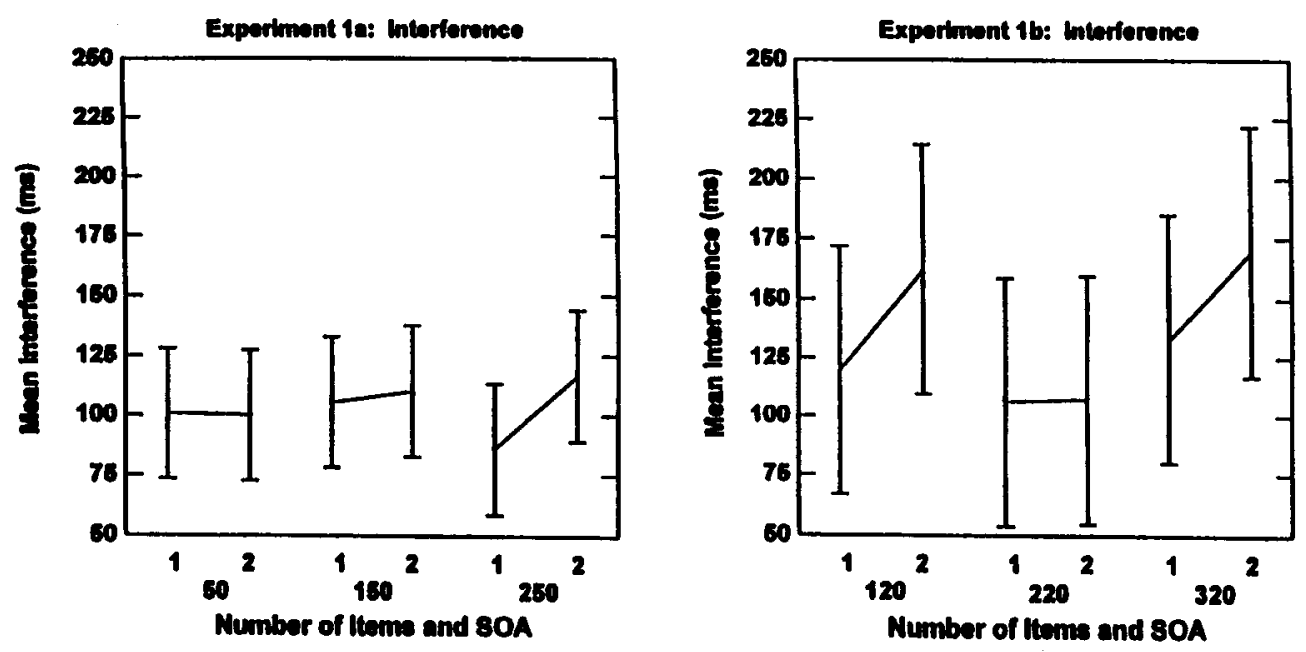

Figure 2. Experiment 1: Stroop interference (incongruent-control) as a function of number of items on a trial (1 vs. 2). The left panel shows the data for Experiment $1 \mathrm{~A}$ as a function of $\mathrm{SOA}(50,150$, or $250 \mathrm{msec})$; the right panel shows the data for Experiment 1B as a function of SOA $(120,220$, or $320 \mathrm{msec})$. The error bars are $95 \%$ confidence intervals derived from an overall $3 \times 2$ ANOVA on the interference scores, calculated according to the Loftus and Masson (1994) formula.

\section{Results and Discussion}

The three panels on the right of Figure 1 display the response latency data from Experiment 1B with each SOA as a separate panel. The story is again simple. Each panel shows very much the same pattern as in Experiment 1A: Incongruent words interfered relative to neutral controls, and trials with one item were responded to faster than those with two items. Even when made more obvious, SOA did not matter. Most critically, two incongruent color words still caused roughly the same amount of interference as did one.

Turning to the supporting ANOVA, once again the only two significant main effects were the number of items $\left[F(1,12)=15.32, M S_{\mathrm{e}}=3,016.91, p<.01\right]$ and the type of items $\left[F(1,12)=103.81, M S_{\mathrm{e}}=6,644.33, p<.001\right]$. Respectively, these reflect that two-item trials $(825 \mathrm{msec})$ were slower than one-item trials $(791 \mathrm{msec})$ by $34 \mathrm{msec}$, and that Stroop interference of $133 \mathrm{msec}$ was apparent for word trials $(874 \mathrm{msec})$ versus control trials $(741 \mathrm{msec})$. Thus, in addition to the usual Stroop interference, there was again a small effect of the number of items. Both of these effects were of roughly the same magnitude as those in Experiment 1A; just as in Experiment 1A, their interaction was nonsignificant $\left[F(1,12)=1.54, M S_{\mathrm{e}}=4,554.32, p=.24\right]$.

There was a marginal effect of SOA $[F(2,24)=2.68$, $M S_{\mathrm{e}}=2,460.86, p=.09$ ], with the $320-\mathrm{msec}$ trials $(821 \mathrm{msec})$ slightly slower than the 220 - and 120-msec trials (both $801 \mathrm{msec}$ ). We see no ready interpretation of this marginal result, so we will not discuss it further. None of the interactions involving SOA were reliable (all $F \mathrm{~s}<1.90$, $p s>.17)$.

The right panel of Figure 2 displays interference at each of the SOAs for both the one-item and the two-item con- ditions. As in Experiment 1A, the $95 \%$ confidence limits in this figure derive from a $3 \times 2$ ANOVA on the incongruentcontrol difference scores. There were no significant effects (all $F \mathrm{~s}<1.93$, $p \mathrm{~s}>.16$ ). Clearly, then, Stroop interference did not increase in moving from one to two incongruent words, regardless of the durations of the two words.

There was reliable interference in Experiment 1B, but again it did not differ between one-item and two-item trials. In addition, there was still a reliable slowing from oneitem to two-item trials, though this was not affected by the type of item. Thus, the slower performance on two-item trials in Experiment 1 A could not have been because those trials contained a noticeable interruption, whereas oneitem trials appeared to be continuous. The interruption was very apparent for both types of trials in Experiment $1 \mathrm{~B}$, yet the cost of having two items was virtually unchanged (37 msec in Experiment $1 \mathrm{~A}$ and $34 \mathrm{msec}$ in Experiment $1 B$ ). Subjects probably pay more attention to the shift between the first and second elements of a trial when a new item appears than when the current item is repeated, but this does not seem to depend on the identity of that new item, including whether it is a word or not.

Experiment 1B thus confirmed Experiment $1 \mathrm{~A}$ and also demonstrated that the cost of two items is quite general. Most important, though, is the general result that seeing two color words on a single Stroop trial does not increase the amount of interference, at least when the two words are presented sequentially. Would two words be more detrimental than one if both words were presented simultaneously? The studies of Kahneman and Chajczyk (1983) and Yee and Hunt (1991), using nonintegrated stimuli, suggest that interference will be unaffected; Experiment 2 generalized to integrated stimuli. 

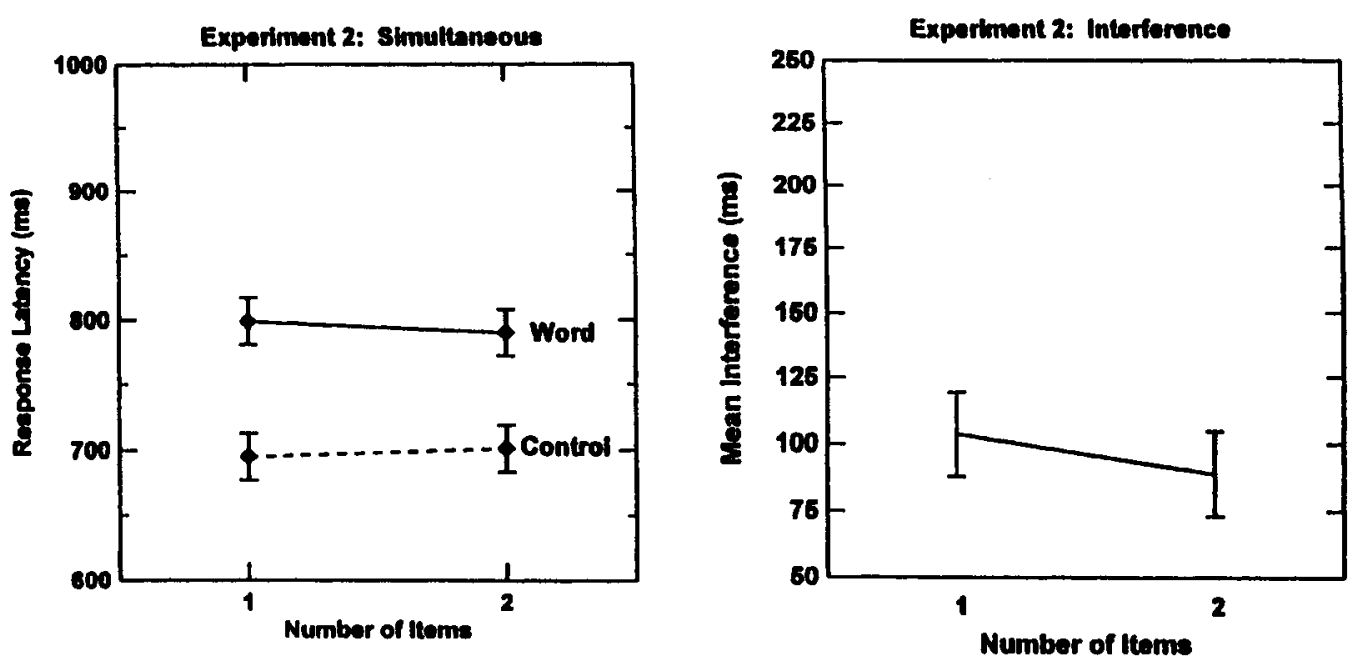

Figure 3. Experiment 2: Mean response latency for incongruent words and for neutral controls (left panel) and mean Stroop interference (right panel) as a function of the number of different items on a trial (1 or 2 ). The error bars are 95\% confidence intervals calculated as described in Figures 1 and 2.

\section{EXPERIMENT 2}

Given that presenting two incongruent words in succession did not alter the amount of interference in naming the common color in which they were presented (relative to the standard single incongruent word), would two words at the same time increase the interference? It is certainly the case that the largest interference effect is observed within $100 \mathrm{msec}$ of simultaneous onset of a single incongruent word and color (Glaser \& Glaser, 1982), peaking at simultaneous onset. Therefore, Experiment 2 was closely patterned after Experiment 1, except that the two words or control items were presented simultaneously, one above the other. On the basis of the findings of Experiments 1 and on the reported results of Kahneman and Chajczyk (1983) and Yee and Hunt (1991), we did not expect to see enhanced interference for simultaneous two-word displays. This second experiment was conducted to bridge our work to the previous studies, once again using integrated stimuli.

\section{Method}

Subjects. Twenty new subjects were selected from the same pool as in Experiment 1. The data from 2 subjects were discarded because their error rates in at least one condition exceeded a preset maximum of .20. Analyses were carried out on the data of the remaining 18 subjects.

Design and Analysis. The two within-subject independent variables were the type of item (incongruent word vs. control) and the number of items ( 1 vs. 2) on each trial. SOA was no longer manipulated. Otherwise, all data-handling procedures were carried out as in Experiment 1. For the latency analysis, responses longer than 2,000 msec (counted as errors) occurred on .004 of all trials. Error data and analyses appear in the Appendix.

Items and Apparatus. The materials and experimental control were identical to those in Experiment 1.

Procedure. Every trial in this experiment was set up as follows. First, there was a 250-msec blank screen, then a 250-msec warning, then a 250-msec blank, and finally the presentation of the stimulus, which remained on the screen until the subject responded. The warn- ing consisted of two rows of eight asterisks presented at the center of the screen on lines 12 and 13 . The stimulus consisted of two words or control strings centered on lines 12 and 13. On single-item trials, the two words or control strings were identical; on doubleitem trials, the two words or control strings were different. Word(s) and color were always incongruent. Both words or control strings on a trial were always in the same color, with the task being to name that color as quickly as possible, ignoring the printed items.

The 96 experimental trials consisted of 24 trials in each of the four conditions. For both incongruent and control single-item conditions (one color word vs. one control item), each item was presented in every other color twice. For both incongruent and control double-item conditions (two different color words vs. two different control items), each possible pair of items was presented in each of the remaining two colors twice, with each of the words in the pair appearing on top once and on the bottom once. Prior to the experimental trials, there were 12 practice trials, 3 trials in each of the four conditions, randomly selected from the set of possible different trials. Accuracy scoring and trial initiation were done as in Experiment 1.

\section{Results and Discussion}

The left panel of Figure 3 displays the response latency data from Experiment 2. As in Experiments $1 \mathrm{~A}$ and $1 \mathrm{~B}$, incongruent words interfered relative to neutral controls. However, trials with two items now took no longer than those with one item, possibly because the display no longer changed. Most critically, two incongruent color words still caused roughly the same amount of interference as did one, even though they now appeared simultaneously.

The results of a supporting $2 \times 2$ ANOVA were straightforward. Only the kind of item on a trial significantly influenced performance $\left[F(1,17)=63.91, M S_{\mathrm{e}}=2,610.80\right.$, $p<.001]$. Overall interference was $96 \mathrm{msec}$. This time, the effect of number of items on a trial was nonsignificant $(F<1)$, as was the interaction $\left[F(1,17)=1.93, M S_{\mathrm{e}}=\right.$ $501.29, p=.18]$.

The right panel of Figure 3 displays interference for both the one- and the two-item conditions. The $95 \%$ confidence limits in this figure derive from an ANOVA comparing the 
two incongruent-control difference scores. The difference was not significant $\left[F(1,17)=1.93, M S_{\mathrm{e}}=1,002.59, p=\right.$ $.18]$, indicating a quite constant Stroop effect whether one or two words were presented on each trial.

In Experiment 1, presenting two to-be-ignored words in quick succession on the same trial did not reliably increase Stroop interference over that caused by a single word. Experiment 2 demonstrated that the same is true when the two words are presented simultaneously, as previously shown for nonintegrated displays. In Experiment 2, interference was $104 \mathrm{msec}$ in the one-word case and $89 \mathrm{msec}$ in the two-word case-magnitudes in the same range as those in Experiments 1A and 1B. Increasing the number of available potential responses on a single trial has little impact on Stroop interference, whether the two items occur successively or simultaneously.

\section{GENERAL DISCUSSION}

Intuitively, one might have imagined that two incompatible color words would cause more interference than one. In all likelihood, this intuition derives from a simple response competition view: The more competing potential responses there are, the slower the actual response should be. With more choices, selection should be harder, but apparently it is not. The present experiments demonstrate this for standard integrated Stroop stimuli, regardless of whether the two words are simultaneous or successive. It is as if the first word processed captures attention, thereby screening any others out. This is precisely the position that Yee and Hunt (1991) took. They maintained that all words activated corresponding long-term memory concepts that then raced to attain sufficient activation to enter working memory. Critically, they argued that "only the word concept that first enters working memory is available to interfere with the color-naming response" (p. 724).

It is noteworthy that the present evidence is consistent with that from earlier work. This evidence was collected in the context of the nonintegrated version of the Stroop task in which word and color are spatially separated. Both Kahneman and Chajczyk (1983, Experiment 4) and Yee and Hunt (1991, Experiments 1 and 3) included conditions that revealed equivalent interference for two color words versus one, measured against a neutral word control. Thus, these findings are general. Whether integrated or separated, simultaneous or successive, measured against a neutral word or a nonword baseline, two incongruent color words do not interfere with color naming more than one.

The present results speak to how we conceive of response competition. In the sort of parallel models proposed by Logan (1980) and by Cohen, Dunbar, and McClelland (1990), information relevant to a response is gathered from each of the color and word dimensions over time. It would now appear that only the first item on which processing is begun on each dimension continues to be processed, at least sufficiently to have an impact in the form of interference. In terms of the weight attached to the word dimension, only the first word attended will have a large enough weight to affect the processing of the print color. One value on each dimension captures attention, excluding all others.

\section{REFERENCES}

Cohen, J. D., Dunbar, K., \& McClelland, J. L. (1990). On the control of automatic processes: A parallel distributed processing account of the Stroop effect. Psychological Review, 97, 332-361.

DYER, F. N. (1973). The Stroop phenomenon and its use in the study of perceptual, cognitive, and response processes. Memory \& Cognition, 1, 106-120.

Glaser, M. O., \& Glaser, W. R. (1982). Time course analysis of the Stroop phenomenon. Journal of Experimental Psychology: Human Perception \& Performance, 8, 875-894.

Gleitman, H. (1991). Psychology (3rd. ed.). New York: Norton.

Graves, R., \& BRADLEY, R. (1987). Millisecond interval timer and auditory reaction time programs for the IBM PC. Behavior Research Methods, Instruments, \& Computers, 19, 30-35.

Graves, R., \& Bradley, R. (1988). More on millisecond timing and tachistoscope applications for the IBM PC. Behavior Research Methods, Instruments, \& Computers, 20, 408-412.

KahNEMAN, D., \& ChaJCzyK, D. (1983). Tests of the automaticity of reading: Dilution of Stroop effects by color-irrelevant stimuli. Journal of Experimental Psychology: Human Perception \& Performance, 9, 497 509.

LofTUS, G. R., \& MAsson, M. E. J. (1994). Using confidence intervals in within-subject designs. Psychonomic Bulletin \& Review, 1, 476-490.

LOGAN, G. D. (1980). Attention and automaticity in Stroop and priming tasks: Theory and data. Cognitive Psychology, 12, 523-553.

MACLEOD, C. M. (1991). Half a century of research on the Stroop effect: An integrative review. Psychological Bulletin, 109, 163-203.

Morton, J. (1969). Categories of interference: Verbal mediation and conflict in card sorting. British Journal of Psychology, 60, 329-346.

Posner, M. I., \& SNyder, C. R. R. (1975). Attention and cognitive control. In R. L. Solso (Ed.), Information processing and cognition: The Loyola symposium (pp. 55-85). Hillsdale, NJ: Erlbaum.

STROOP, J. R. (1935). Studies of interference in serial verbal reactions. Journal of Experimental Psychology, 18, 643-662.

Treisman, A. M. (1969). Strategies and models of selective attention. Psychological Review, 76, 282-299.

YanTIS, S. (1993). Stimulus-driven attentional capture. Current Directions in Psychological Science, 2, 156-161.

YEE, P. L., \& HUNT, E. (1991). Individual differences in Stroop dilution: Tests of the attention-capture hypothesis. Journal of Experimental Psychology: Human Perception \& Performance, 17, 715-725.

\section{APPENDIX}

Error Proportions as a Function of Type of Item, Number of Items, and Stimulus Onset Asynchrony (SOA)

\begin{tabular}{rrlll}
\hline SOA & One Word & One Control & Two Words & Two Controls \\
\hline \multicolumn{5}{c}{ Experiment 1A } \\
50 & .039 & .009 & .051 & .017 \\
150 & .044 & .025 & .040 & .011 \\
250 & .048 & .009 & .038 & .019 \\
& & Experiment 1B & \\
120 & .051 & .018 & .062 & .025 \\
220 & .070 & .038 & .068 & .034 \\
320 & .070 & .025 & .069 & .006 \\
& & Experiment 2 & \\
All & .029 & .011 & .022 & .013 \\
\hline
\end{tabular}




\section{APPENDIX (Continued)}

\section{Error Analyses}

Experiment 1A. Only the main effect of type of items was significant $\left[F(1,18)=17.60, M S_{\mathrm{e}}=26.00, p<.001\right]$, with words $(.043)$ producing more errors than control items $(.015)$, reflecting standard Stroop interference (all other $F \mathrm{~s}<1.10$ ).

Experiment 1B. Again, only type of item resulted in a reliable effect $\left[F(1,12)=14.17, M S_{e}=.003, p<.01\right]$. There were, as usual, more errors on the word trials $(.065)$ than on the control item trials (.024), a Stroop interference effect of .041 (all other $\left.F_{\mathrm{s}}<1\right)$.

Experiment 2. The only factor that influenced error rate was the kind of item on a trial $\left[F(1,17)=4.86, M S_{\mathrm{e}}=.001, p<.05\right]$. Errors showed a .014 increase from control trials $(.012)$ to word trials $(.026$; all other $F \mathrm{~s}<1$ ).

(Manuscript received May 25, 1994;

revision accepted for publication December 26, 1996.) 